\title{
Thick Single Grain Silicon Formation with Microsecond Green Laser Crystallization
}

\author{
A. Arslan ${ }^{\mathrm{a}}$, H. J. Kahlert ${ }^{\mathrm{b}}$, P. Oesterlin ${ }^{\mathrm{b}}$, D. T. Mofrad ${ }^{\mathrm{a}}$, R. Ishihara ${ }^{\mathrm{a}}$, Kees Beenakker ${ }^{\mathrm{a}}$ \\ ${ }^{a}$ Department of Microelectronics, Delft University of Technology \\ Delft, 2628CT, The Netherlands \\ ${ }^{\mathrm{b}}$ Innovavent GmbH, Göttingen, 37085, Germany
}

$625 \mathrm{~nm}$ thick a-Si layer was crystallized by using microsecond pulsed green laser with wavelength of $515 \mathrm{~nm}$. At least $8 \mu \mathrm{m}$ size grains were formed using location controlled single grain technique at room temperature. Energy density window for crystallization and ablation were compared for pulse durations of $300 \mathrm{~ns}, 1000 \mathrm{~ns}$ and $1200 \mathrm{~ns}$.

\section{Introduction}

Thin-film Si photo-diodes are attractive as it can be monolithically stacked upon CMOS FETs or TFTs. The photo-diodes with 3D-IC configuration will provide high fill-factor and more smartness in image sensors and solar-cells (1). For these applications, thick silicon layer $(>500 \mathrm{~nm})$ is needed in order to increase the light sensitivity of the photodiode especially at longer wavelengths $(>400 \mathrm{~nm})$. Amorphous-Si could be used as the layer, however, due to the amorphous nature, mobility is very low $\left(1 \mathrm{~cm}^{2} / \mathrm{Vs}\right)$ resulting in imaging lag problem. Poly-Si TFTs will improve mobility but random grain boundaries in the layer trap the charge carriers and lowers quantum efficiency. Single grain technology offers higher mobility and sensitivity by controlling the position of the grain boundaries. Gate of the TFTs and light sensitive region of the photodiodes are placed inside these grains.

The $\mu$-Czochralski process has been developed in TU Delft and enables 2D locationcontrol of single grain using pulsed-laser crystallization (2). $6 \mu \mathrm{m}$ Si grains have been obtained at predetermined positions with $250 \mathrm{~nm}$ thick a-Si crystallized with $\mathrm{XeCl}$ excimer laser $(308 \mathrm{~nm})$ with a pulse duration of $25 \mathrm{~ns}$ and substrate heating of $450^{\circ} \mathrm{C}$. We used a longer pulse duration of $250 \mathrm{~ns}$ and succeeded to crystallize $1 \mu \mathrm{m}$ thick a-Si with a maximum grain size of 6 microns (3). Yet, the process window was very narrow due to agglomeration. In general, longer pulse duration and substrate heating helps in increasing the maximum melt depth and hence crystallization of the thick Si layer; however use of millisecond laser will introduce severe thermal damage to underlying substrate. Moreover, substrate heating is not convenient for crystallization of silicon layer on plastic or glass substrates.

In this study, we used microsecond pulsed green laser (Yb:YAG Laser JenaRas Asama) (4) for crystallization of a $625 \mathrm{~nm}$ thick silicon layer at room temperature. The laser has a wavelength of $515 \mathrm{~nm}$ and a pulse frequency of $10 \mathrm{kHz}$. Grain size, energy density window and crystallographic orientation were investigated. 


\section{D Location Controlled Single Grain Formation}

Single grain process flow starts with oxidation of Si-wafer. $1 \mu \mathrm{m} \times 1 \mu \mathrm{m}$ size cavities are patterned in $750 \mu \mathrm{m}$ thick thermal $\mathrm{SiO}_{2}$ layer using (Figure 1.a). Cavity diameter is reduced to $100 \mathrm{~nm}$ (called grain-filter (GF)) with depositing $850 \mathrm{~nm}$ tetra ethyl-orthosilicate (TEOS) using plasma-enhanced chemical vapor deposition (PECVD) at $350{ }^{\circ} \mathrm{C}$. After defining the cavities which later serve as the grain filter, $625 \mathrm{~nm}$ thick amorphous silicon (a-Si) is deposited by low-pressure plasma chemical vapor deposition (LPCVD) on different wafers. When the a-Si layer is exposed to laser, silicon layer melts however unmelted silicon seed stays at the bottom of the cavity and crystallization starts from this filter (Figure 1.b). Subsequently, the molten silicon layer solidifies to polysilicon with controlled grain boundaries. Grain filters are located with a certain pitch. Grain size is defined by the pitch of the grain filters and laser energy. If the laser energy is high enough, crystallized adjacent grains meet and forms grain boundaries. As stated above, in single grain growth, the position of the grain boundaries are controlled unlike polysilicon.

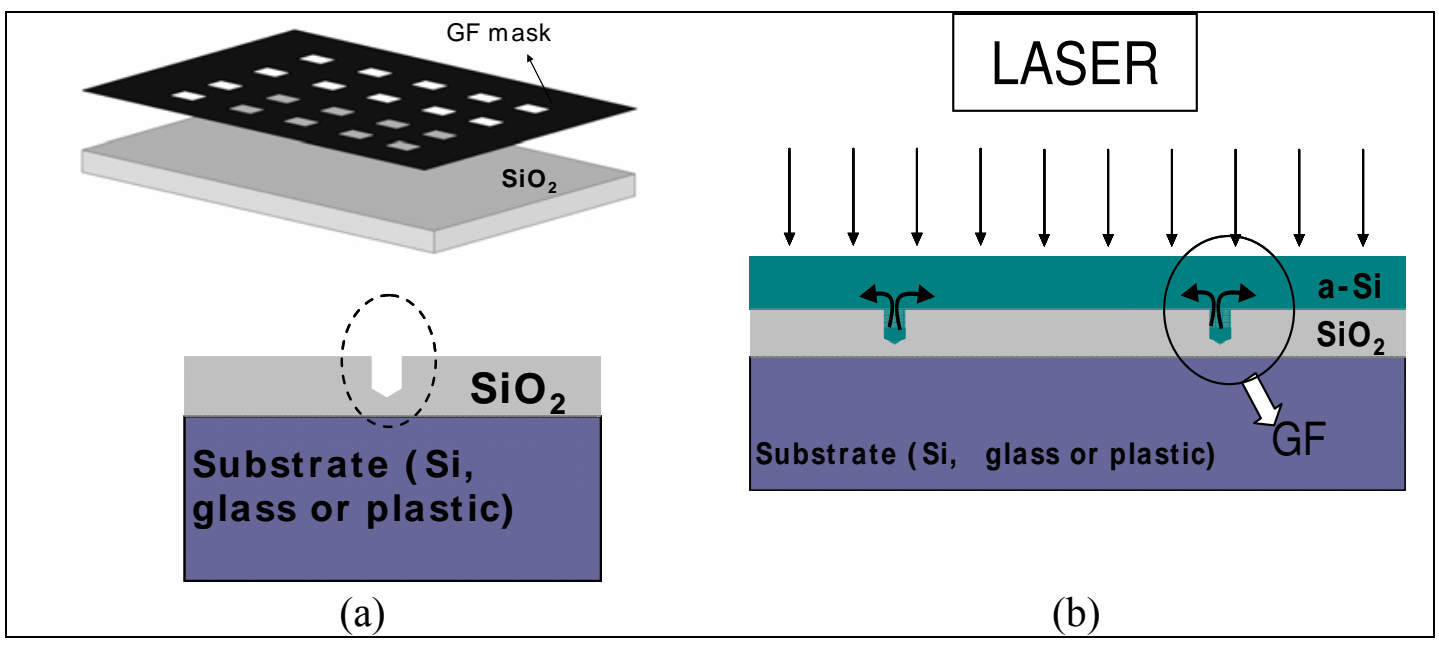

Figure 1. Single grain formation with $\mu$-Czochralski process.

In order to achieve high electrical and optical performance, the active area of the devices must be located in each single grain since at the random grain boundaries atoms are highly disordered and limit the carrier mobility. When laser shoots the a-Si layer, crystallization occurs only at the grain filter locations. Silicon islands are placed at the predetermined grain locations.

\section{Crystallization Experiments with Microsecond Green Laser}

The pulsed green laser has adjustable pulse duration and we used $300 \mathrm{~ns}, 1000 \mathrm{~ns}$ and $1200 \mathrm{~ns}$ pulse durations in crystallization. The full width half maximum (FWHM) of the beam was $\sim 30 \mu \mathrm{m}$ in Gaussian shape width and $2 \mathrm{~mm}$ in length in top-hat shape. Required crystallization energy density and ablation threshold were investigated for these three pulse durations. 


\section{$\underline{\text { Pulse duration of } 300 \mathrm{~ns}}$}

For $300 \mathrm{~ns}$, we started with $1300 \mathrm{~mJ} / \mathrm{cm}^{2}$ and we increased the energy density up to $3300 \mathrm{~mJ} / \mathrm{cm}^{2}$. It was found that crystallization started at $1900 \mathrm{~mJ} / \mathrm{cm}^{2}$ and $4 \mu \mathrm{m}, 5 \mu \mathrm{m}$ and $6 \mu \mathrm{m}$ size grains formed (Figure 2.a). At this energy density $7 \mu \mathrm{m}$ and $8 \mu \mathrm{m}$ size grain formation started (Figure 2.b) but full growth was obtained at $2100 \mathrm{~mJ} / \mathrm{cm}^{2}$ and 2300 $\mathrm{mJ} / \mathrm{cm}^{2}$ (Figure 2.c and Figure 2.d), respectively. In the figure, it is shown that $4 \mu \mathrm{m}$ size grains have square shape however the laser pulse covered the $8 \mu \mathrm{m}$ size grain filters only in $\mathrm{y}$ direction but could not cover the area in $\mathrm{x}$ direction. Therefore, while the grain size reached $8 \mu \mathrm{m}$ in $\mathrm{y}$ direction, it could only reach the half size in $\mathrm{x}$. Grain shape in $\mathrm{x}$ direction can be improved using a wider pulse. It is observed that at this energy density, $300 \mathrm{~ns}$ pulse caused cracks in the silicon layer due to high stress. Ablation threshold was found to be $3100 \mathrm{~mJ} / \mathrm{cm}^{2}$ (Figure 3) for $300 \mathrm{~ns}$ pulse duration. The thick layers require higher energy density to fully melt the layer, however because of the relatively short pulse duration the surface temperature increases drastically and results in agglomeration/ablation before the grain-filters are fully melted.

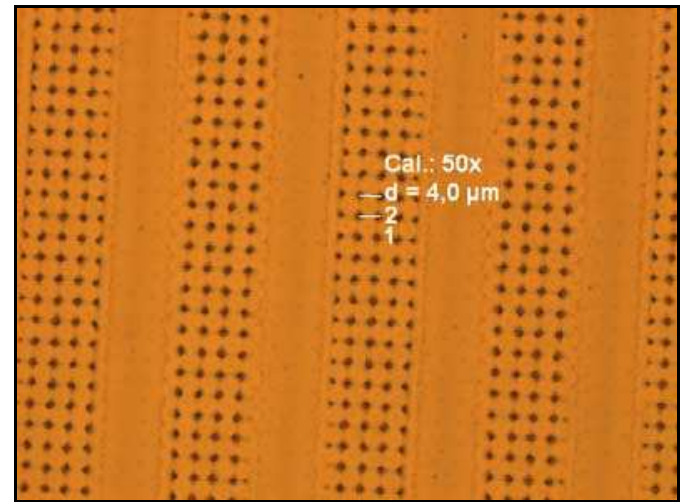

(a)

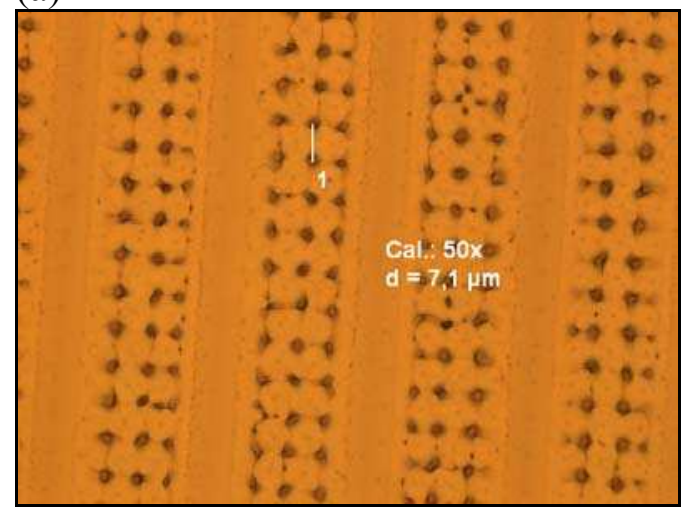

(c)

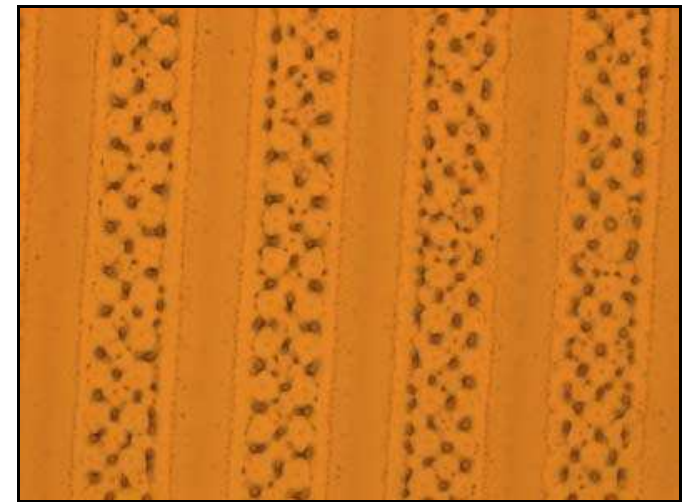

(b)

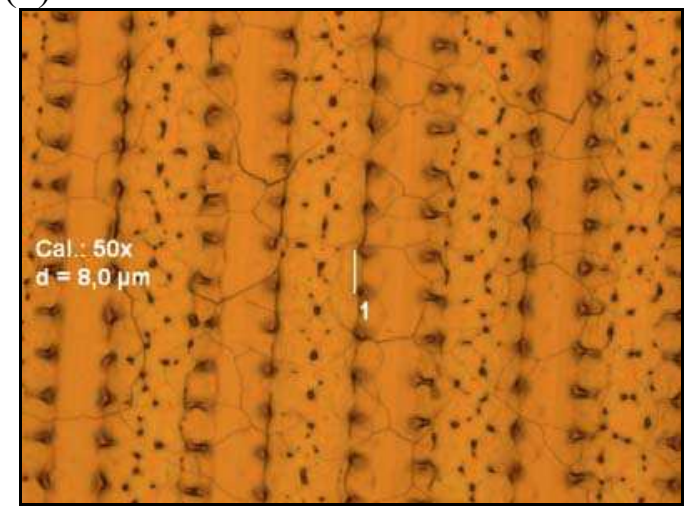

(d)

Figure 2. Microscope picture of SG arrays formed using $300 \mathrm{~ns}$ pulse length (a) $4 \mu \mathrm{m}$ size grain formation at energy density of $1900 \mathrm{~mJ} / \mathrm{cm}^{2}$, (b) $8 \mu \mathrm{m}$ size grain formation starts at energy density of $1900 \mathrm{~mJ} / \mathrm{cm}^{2}$, (c) $7 \mu \mathrm{m}$ size grain formation at energy density of 2100 $\mathrm{mJ} / \mathrm{cm}^{2}$, (d) $8 \mu \mathrm{m}$ size grain formation at energy density of $2300 \mathrm{~mJ} / \mathrm{cm}^{2}$. 


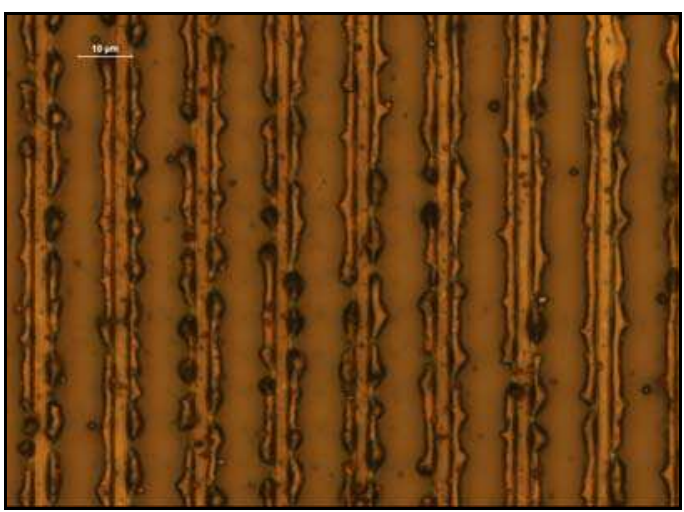

(a)

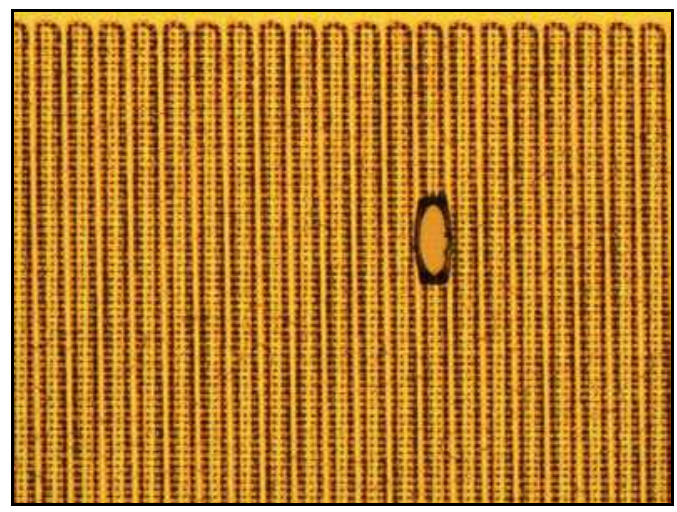

(b)

Figure 3. Microscope picture of ablated $625 \mathrm{~nm}$ thick a-Si after irradiated with $300 \mathrm{~ns}$ green laser pulse at $3100 \mathrm{~mJ} / \mathrm{cm}^{2}$ (a) pulse width is $6 \mu \mathrm{m}$, (b) pulse width is $30 \mu \mathrm{m}$.

\section{$\underline{\text { Pulse duration of } 1000 \mathrm{~ns}}$}

Next, the same wafer was shot with $1000 \mathrm{~ns}$ pulse length to observe the change in crystallization and ablation threshold. Energy density was swept from $1700 \mathrm{~mJ} / \mathrm{cm}^{2}$ to $4500 \mathrm{~mJ} / \mathrm{cm}^{2}$. With the longer pulse duration, $4 \mu \mathrm{m}$ and $5 \mu \mathrm{m}$ size grains were obtained with energy density of $2300 \mathrm{~mJ} / \mathrm{cm}^{2}$ (Figure 4.a). At this energy density, $6 \mu \mathrm{m}, 7 \mu \mathrm{m}$ and $8 \mu \mathrm{m}$ size grain formation started but at $2500 \mathrm{~mJ} / \mathrm{cm}^{2}$ grains reached to their full size (Figure 4.b).With $1000 \mathrm{~ns}$ pulse, ablation threshold found at energy density of 4100 $\mathrm{mJ} / \mathrm{cm}^{2}$. Process window has been improved with longer pulse.

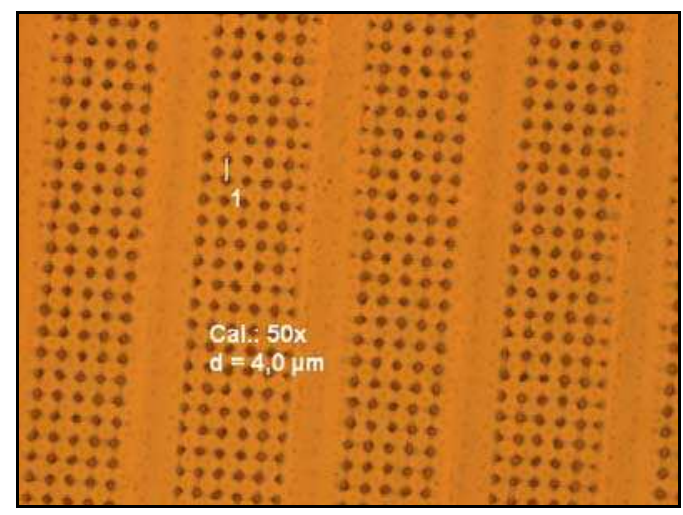

(a)

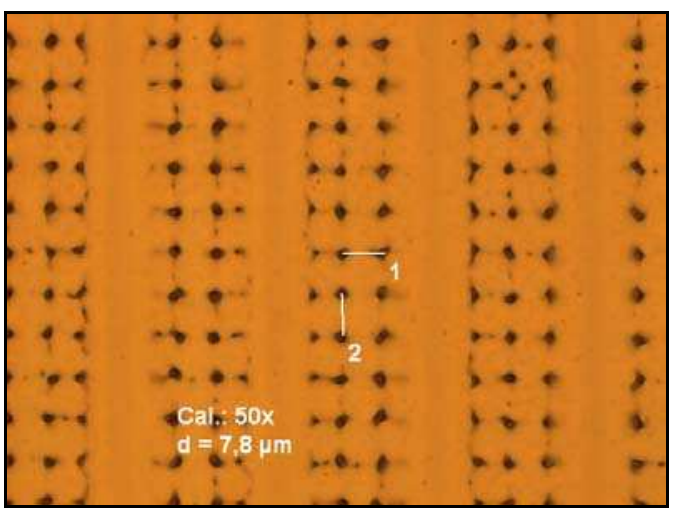

(b)

Figure 4. Microscope picture of single grain arrays formed using 1000 ns pulse length (a) $4 \mu \mathrm{m}$ size grain formation at energy density of $2300 \mathrm{~mJ} / \mathrm{cm}^{2}$, (b) $8 \mu \mathrm{m}$ size grain formation at energy density of $2500 \mathrm{~mJ} / \mathrm{cm}^{2}$.

\section{$\underline{\text { Pulse duration of } 1200 \mathrm{~ns}}$}

Last crystallization experiment was done with pulse duration of 1200 ns. Energy density was swept from $2000 \mathrm{~mJ} / \mathrm{cm}^{2}$ to $6000 \mathrm{~mJ} / \mathrm{cm}^{2}$. Complete growth of grains with different sizes was obtained at $2600 \mathrm{~mJ} / \mathrm{cm}^{2}$. Microscope picture of the $7 \mu \mathrm{m}$ and $8 \mu \mathrm{m}$ size single grain arrays are shown in Figure 5. Ablation started at the energy density higher than $5200 \mathrm{~mJ} / \mathrm{cm}^{2}$ and shown in Figure 6. $1200 \mathrm{~ns}$ pulse length enabled even wider process window. Therefore, we can improve the grain size to larger than $8 \mu \mathrm{m}$ in our future experiments. 


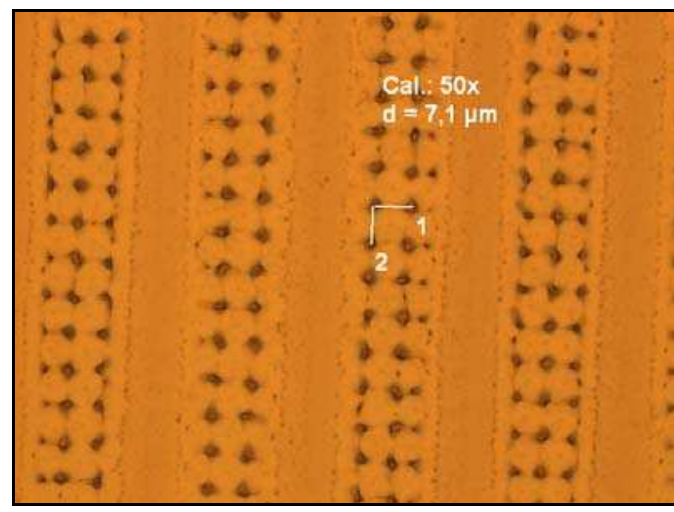

(a)

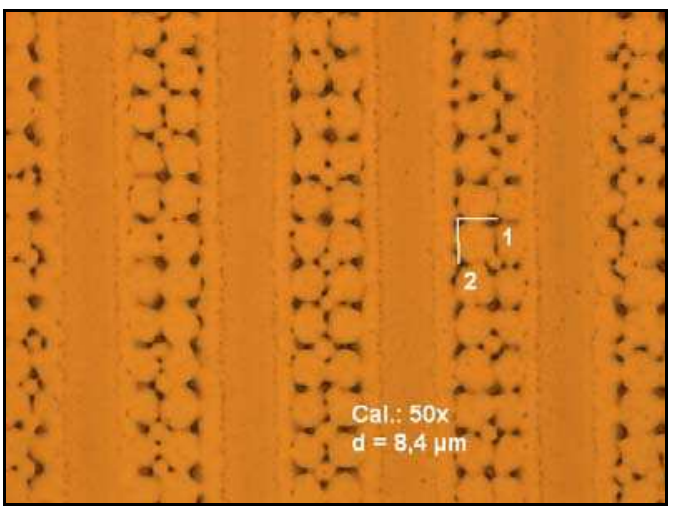

(b)

Figure 5. Microscope picture of single grain arrays formed using $1200 \mathrm{~ns}$ pulse length at energy density of $2600 \mathrm{~mJ} / \mathrm{cm}^{2}$ (a) $7 \mu \mathrm{m}$ size grain formation, (b) $8 \mu \mathrm{m}$ size grain formation.

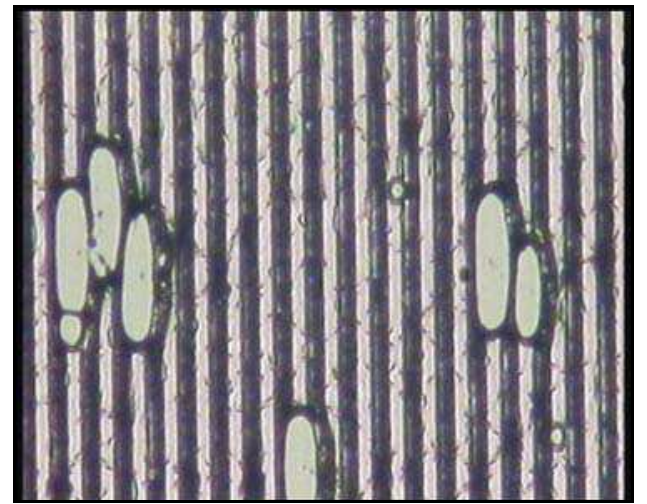

Figure 6. Microscope picture of ablated $625 \mathrm{~nm}$ thick a-Si after irradiated with $1200 \mathrm{~ns}$ green laser pulse at energy density higher than $5200 \mathrm{~mJ} / \mathrm{cm}^{2}$.

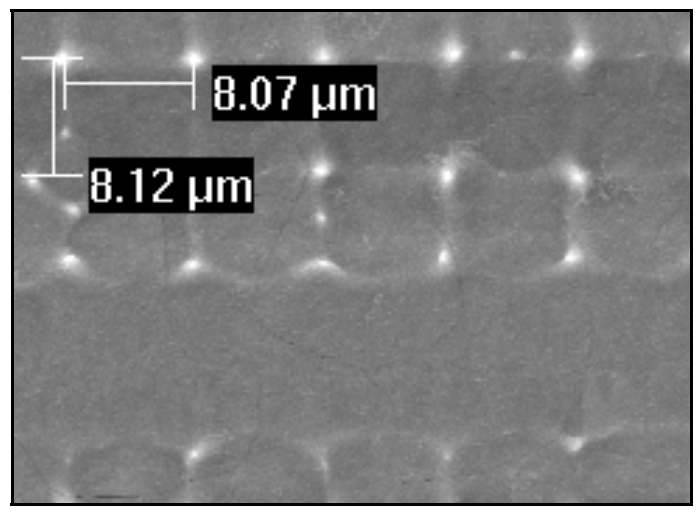

(a)

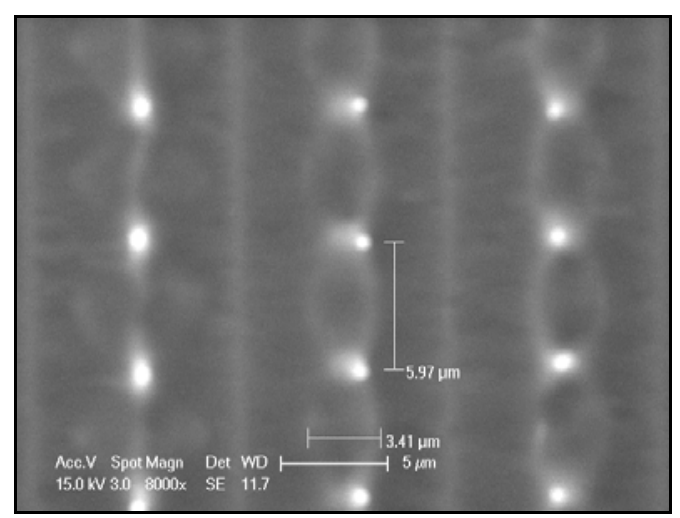

(b)

Figure 7. SEM picture of $625 \mathrm{~nm}$ thick (a) $8 \mu \mathrm{m}$ size single grain, pulse FWHM of $30 \mu \mathrm{m}$, (b) $6 \mu \mathrm{m}$ size grain, pulse FWHM of $6 \mu \mathrm{m}$.

With SEM it was confirmed that with $30 \mu \mathrm{m}$ FWHM beam, the grain was formed from pre-determined position of the grain-filter and the size of the grain in both $\mathrm{x}$ and $\mathrm{y}$ directions reaches $8 \mu \mathrm{m}$ (Figure 7.a). 
As stated above, when the pulse size is not wide enough to cover grain filters, gains cannot reach to their full size even though the energy density is sufficient. This can be seen in Figure 7.b where the pulse width was $6 \mu \mathrm{m}$ in width and the pitch of the grain filter is $6 \mu \mathrm{m}$. As seen in Figure 7.b, since the grain filter could not be covered completely in $\mathrm{x}$ direction, grain size could only reach to half in width but in y direction, grain size was $6 \mu \mathrm{m}$ as expected.

Figure 8 summarizes the change in grain size with energy density and pulse duration. As seen in the figure, less energy is needed when the pulse is short $(5,6)$. However, short pulse (300 ns) cause higher stress in the layer and crack at $2300 \mathrm{~mJ} / \mathrm{cm}^{2}$.

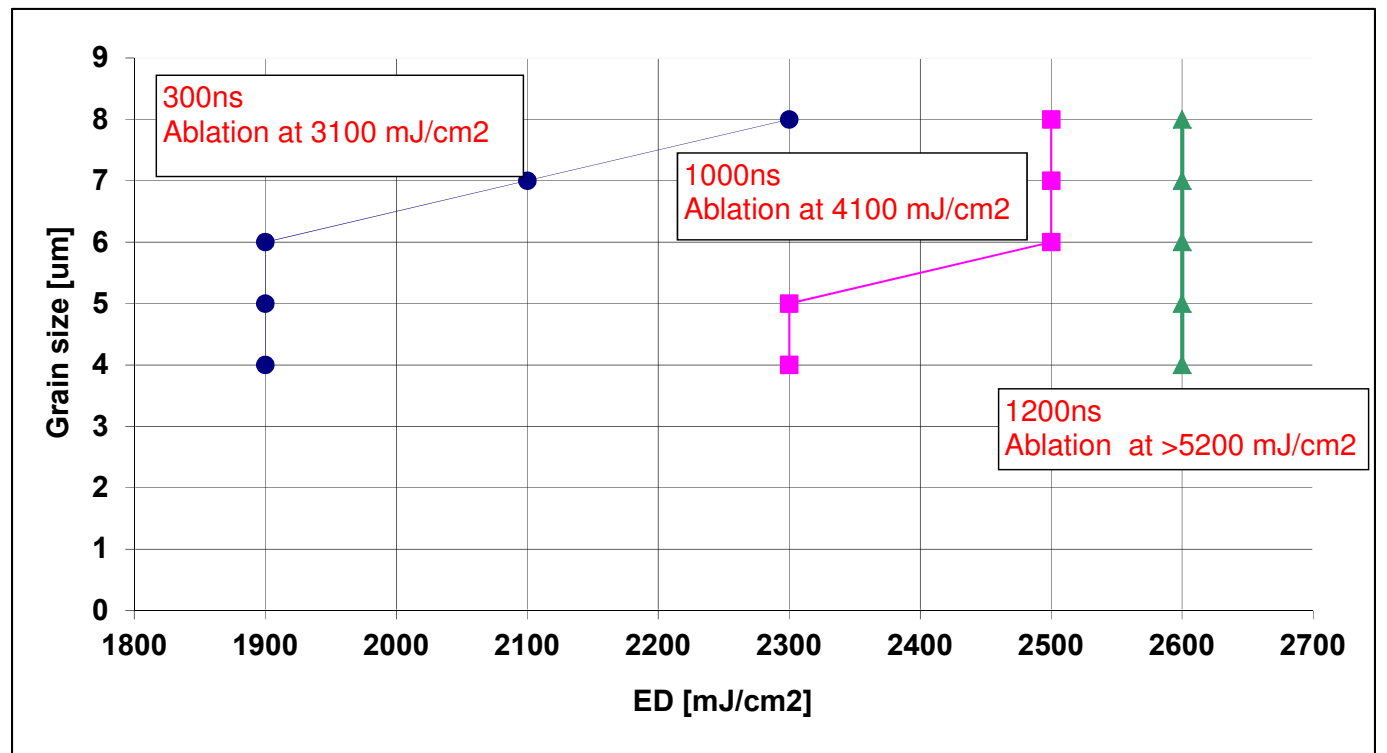

Figure 8. Grain size vs. Energy density graph for pulse durations of 300 ns, 1000 ns and $1200 \mathrm{~ns}$

For imaging of the crystallized silicon with optical microscope, we used differential interference contrast (DIC) filter (DIC Schieber 1105-193). Differential interference contrast method displays a contrast in the image using the refraction index difference in different areas of the specimen. $8 \mu \mathrm{m}$ size single grain areas are marked with dashed lines in Figure 9. The bright dots show the corners where neighbor grains collide. One of the grains is zoomed in and showed on the figure. The contrast variation inside the single grains is due to planar coincident site lattice grain boundaries (CSL-GBs).

Electron back-scattering diffraction (EBSD) images are in Figure 10. Inverse pole figure and image quality maps show that random grain boundaries are obtained only between the Si islands and boundaries inside the silicon island is predominantly $\Sigma 3$ and slightly $\Sigma 27$ CSL-GBs which effect electrical performance much less than the random grain boundaries $(7,8)$. 


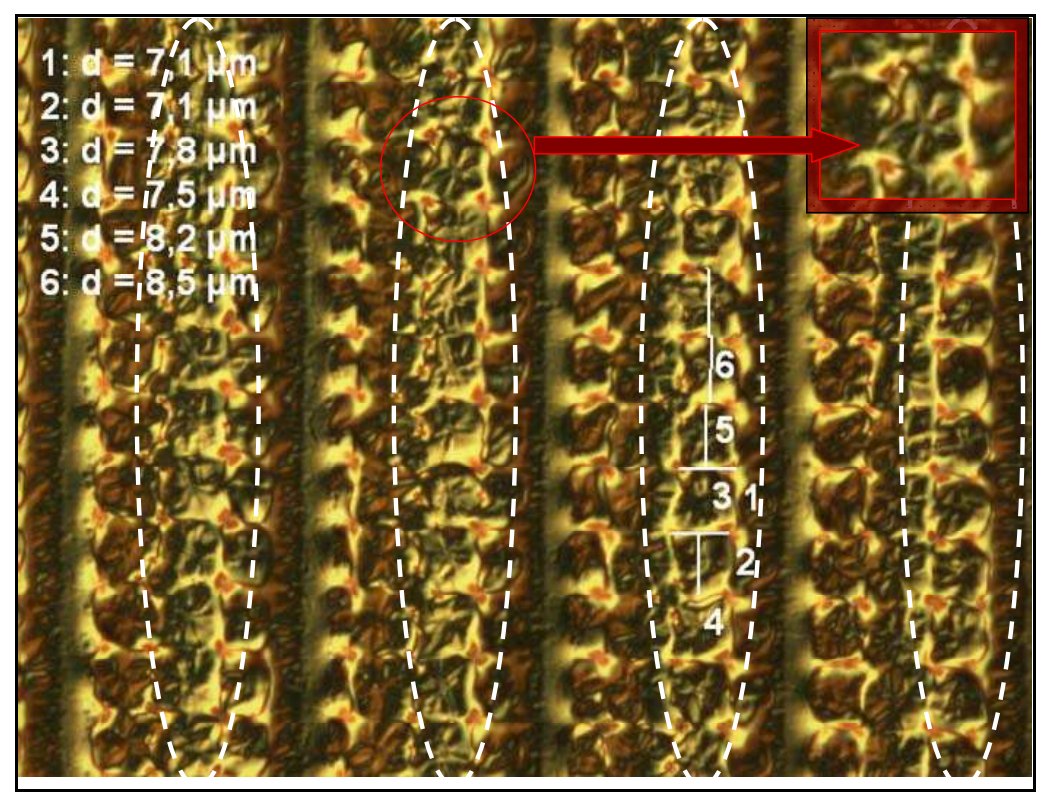

Figure 9. Microscope picture of $8 \mu \mathrm{m}$ size single grain analyzed with differential interference contrast (DIC) filter.

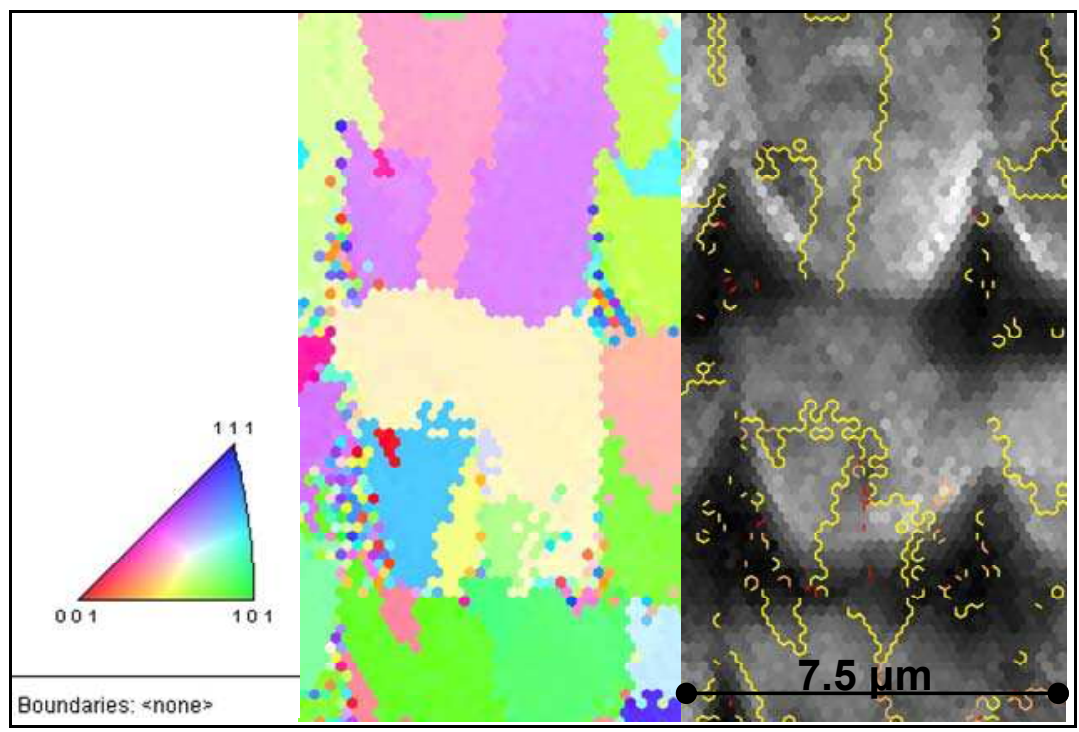

Figure 10. EBSD mapping of location-controlled grains showing $\Sigma 3$ CSL-GBs inside the grain.

\section{Conclusion}

Microsecond green laser was used to crystallize $625 \mathrm{~nm}$ thick a-Si layer with single grain technique at room temperature. Grain filters were placed as an array with $4 \mu \mathrm{m}$ to 8 $\mu \mathrm{m}$ pitch. $300 \mathrm{~ns}, 1000 \mathrm{~ns}$ and $1200 \mathrm{~ns}$ pulses were used and maximum $8 \mu \mathrm{m}$ size grains were successfully formed at each pulse duration with very wide energy window. Ablation window improves with longer pulse duration. This enables us to crystallize grains larger than $8 \mu \mathrm{m}$. Optical microscope pictures and SEM images are presented to show the single grain formation and the size variation. DIC and EBSD analysis results prove that random grain boundaries only present between grains and only CSL-GBs are inside the grains which have very low electrical activity than random GBs. 


\section{Acknowledgments}

We would like to express sincere thanks to all DIMES clean room staffs in DIMES Technology Center and CATRENE (Cluster for Application and Technology Research in Europe on Nanoelectronics) for the support of this project.

\section{References}

1. R. Ishihara et al., Solid-State Electronics, 71 (2012)

2. V. Rana, PhD Thesis, TU Delft, ISBN: 90-6464-038-6.

3. A. Arslan et al., Proc. of SPIE Medical Imaging Conference, 7961, Orlando, USA (2011).

4. Y. Arai et al., 17th Int. Conf. on Advanced Thermal Processing of Semiconductors (2009).

5. R. Ishihara et al., J. Crystal Growth, 299 (2007).

6. R. Ishihara et al., Thin Solid Films, 487 (2005).

7. N. Matsuki et al., Proc. of the $14^{\text {th }}$ International Display workshop, 2 (2007).

8. N. Matsuki et al., Applied Physics Letters, 93 (2008) 